\title{
Frost flower formation on sea ice and lake ice
}

\author{
Robert W. Style ${ }^{1}$ and M. Grae Worster ${ }^{1}$ \\ Received 22 January 2009; revised 20 April 2009; accepted 6 May 2009; published 10 June 2009.
}

[1] Frost flowers are clusters of ice crystals found on freshly formed sea ice and occasionally on frozen lakes. They belong to a class of vapour-related phenomena that includes freezing fog, hoar frost and dew. It has hitherto been supposed that they form by condensation from a supersaturated atmosphere or from water wicked up through porous sea ice. Here we show that they can form on solid, pure ice sublimating into an unsaturated atmosphere. We derive a general regime diagram showing the atmospheric conditions under which the different vapour-related phenomena occur and confirm our predictions of frost-flower formation with a series of laboratory experiments. Our results can be used in climate models to predict occurrence of frost flowers, which significantly enhance albedo and provide the substrate for chemical production of ozone-depleting bromine monoxide, and in paleo-climate reconstructions by relating observations of sea-salt aerosols in ice cores to atmospheric conditions. Citation: Style, R. W., and M. G. Worster (2009), Frost flower formation on sea ice and lake ice, Geophys. Res. Lett., 36, L11501, doi:10.1029/2009GL037304.

\section{Introduction}

[2] Frost flowers are beautiful fern-like formations of pure ice crystals found on thin sea ice less than a few centimetres thick (Figure 1). They are covered in brine and overall are extremely salty (about 120 psu [Perovich and Richter-Menge, 1994]) compared with seawater (less than $35 \mathrm{psu}$ ). They have excited recent interest as a potentially important source of sea-salt-derived aerosols in polar regions [Rankin et al., 2002], following satellite observations of bromine monoxide (BrO), a significant ozone-depleting molecule, emanating from fields of frost flowers [Kaleschke et al., 2004]. The common association of frost flowers with porous sea ice and the fact that external vaporizers have been used to create frost flowers in laboratory cold rooms have led scientists to suggest that brine transport through the pores of sea ice is important for frost flower formation [Perovich and Richter-Menge, 1994; Martin et al., 1995] and that an upwind source of open water may also play a role in their growth [Perovich and Richter-Menge, 1994]. However, here we show theoretically and confirm experimentally that frost flowers can grow on pure, solid ice in a cold, still, dry atmosphere. A surprising and important result is that frost flowers form on ice surfaces that are sublimating, unlike hoar frost condensing from a supersaturated atmosphere, to which frost flowers have been compared. By revealing the conditions of temperature and humidity under which frost flowers form,

\footnotetext{
${ }^{1}$ Institute of Theoretical Geophysics, Department of Applied Mathematics and Theoretical Physics, University of Cambridge, Cambridge, UK.

Copyright 2009 by the American Geophysical Union. 0094-8276/09/2009GL037304\$05.00
}

our findings pave the way for physically based estimation within climate models of sea-salt aerosol and $\mathrm{BrO}$ production and inform the reconstruction of paleo-climate conditions from the abundances of salts contained in Antarctic ice cores [Wolff et al., 2003].

\section{Theory}

[3] Since frost flowers have also been observed on freshwater lakes [Domine et al., 2005], we ignore any influence of salt and consider the evolution of a pure ice surface and the air above it (Figure 2). The humidity of the air and the phase behaviour of its water content are determined by reference to the Clausius-Clapeyron equation for the saturation vapour density

$$
\rho_{\text {sat }}(T)=\rho_{\text {sat }}\left(T_{\infty}\right) \frac{T_{\infty}}{T} \exp \left[-\frac{M L}{R}\left(\frac{1}{T}-\frac{1}{T_{\infty}}\right)\right]
$$

as a function of temperature $T$, where $M$ is the molar mass of water, $L$ is the latent heat of vaporization per unit mass, $R$ is the gas constant and $T_{\infty}$ is the temperature of the far-field atmosphere. Because heat and water vapour have almost the same diffusivity in air (approx $1.8 \times 10^{-5} \mathrm{~m}^{2} \mathrm{~s}^{-1}$ and $1.5 \times$ $10^{-5} \mathrm{~m}^{2} \mathrm{~s}^{-1}$ respectively), they are transported almost identically. By taking the diffusivities to be equal, we can write the variations of temperature and vapour density with height $z$ above the ice and time $t$ as

$$
T-T_{\infty}=\left(T_{i}-T_{\infty}\right) f(z, t)
$$

and

$$
\rho-\rho_{\infty}=\left(\rho_{i}-\rho_{\infty}\right) f(z, t),
$$

where $\rho_{\infty}$ and $\rho_{i}=\rho_{\text {sat }}\left(T_{i}\right)$ are the vapour densities in the far field and adjacent to the ice respectively. The important observation is that $T$ and $\rho$ have the same functional form.

[4] In the absence of ambient air flow, $f(z, t)$ can be expressed in terms of error functions, typical of diffusioncontrolled transport [Worster, 2000], and has the shape shown schematically in Figure 2. However still air is not necessary for our argument and our results are not affected by air movements such as those induced by the density change associated with the sublimation of ice or caused by blowing winds.

\section{Results}

[5] Importantly, the temperature dependence of the saturation vapour density can give rise to a region above the ice in which the air is supersaturated while the far-field atmosphere is unsaturated [Reed and LaFleur, 1964], as shown schematically by the dashed curve in Figure 2. It is this local 


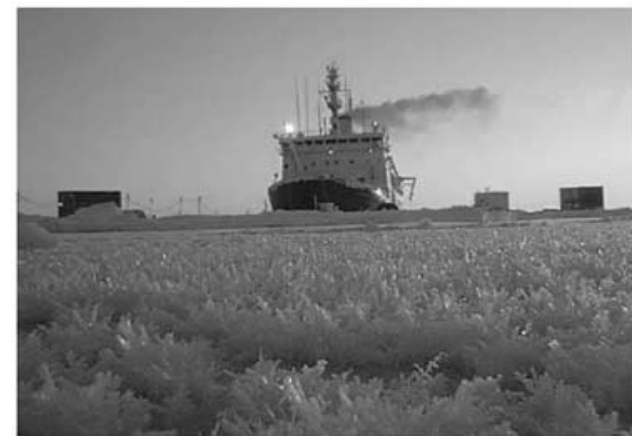

(a)

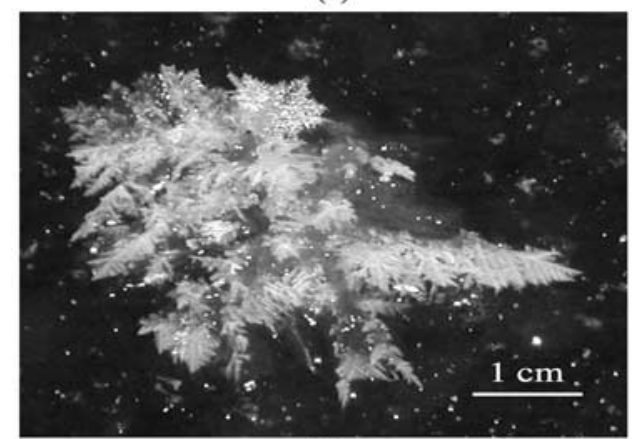

(b)

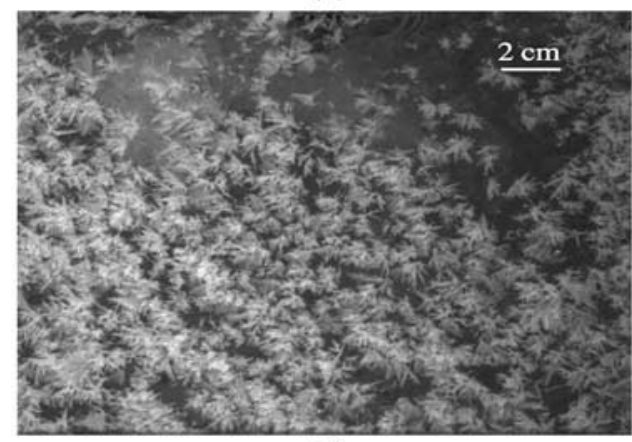

(c)

Figure 1. (a) A field of frost flowers photographed during the SHEBA expedition (1997). (b) A single frost flower on a refrozen ice hole on Adventfjord Svalbard. (c) Frost flowers on the surface of freshwater ice in our cold room.

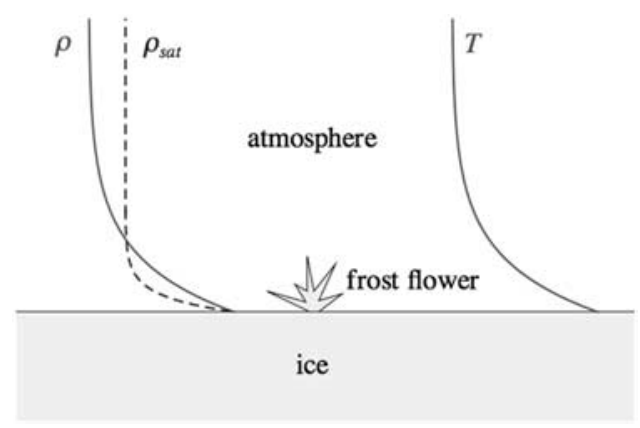

Figure 2. Schematic diagram of the temperature $T$ and vapour density $\rho$ in the air above ice sublimating into a relatively cold, dry atmosphere. The dashed curve indicates the saturation vapour density $\rho_{\text {sat }}(T)$ and shows that a region of supersaturation can develop above the ice into which frost flowers can grow.

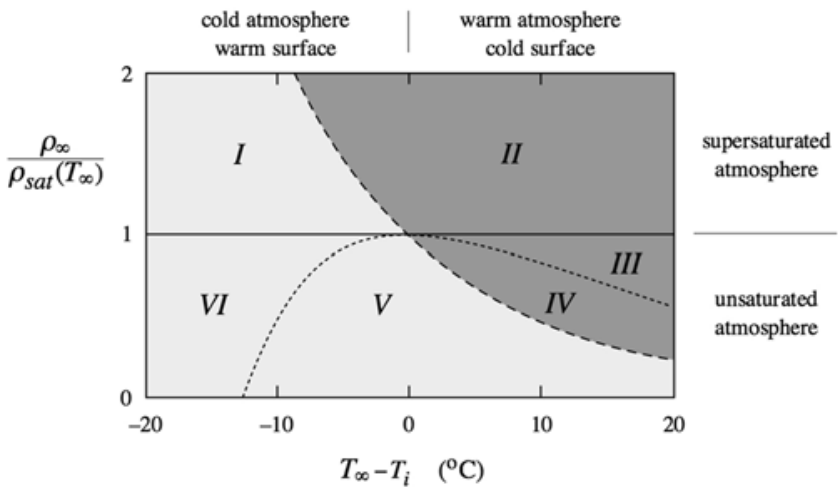

Figure 3. The environmental conditions of relative humidity $\rho_{\infty} / \rho_{\text {sat }}\left(T_{\infty}\right)$ and temperature difference $T_{\infty}-T_{i}$ between the atmosphere and an ice surface under which different evaporation/sublimation processes can occur, as described in Table 1 . Values used are $M L=5.09 \times 10^{4} \mathrm{~J}$ $\mathrm{mol}^{-1}, R=8.31 \mathrm{~J} \mathrm{~K}^{-1} \mathrm{~mol}^{-1}$ and $T_{\infty}=271 \mathrm{~K}$, giving $m=$ 22.6. A qualitatively similar diagram applies to a water/air interface, for which $M L=4.5 \times 10^{4} \mathrm{~J} \mathrm{~mol}^{-1}$.

supersaturation that gives rise to frost flowers. It is analogous to the local constitutional supercooling [Rutter and Chalmers, 1953; Huppert and Worster, 1985] that can occur during the solidification of alloys but there are significant differences. Constitutional supercooling occurs because the diffusivity of a solute in liquid is much less than the diffusivity of heat [Worster, 2000], and can only occur during solidification, not during melting or dissolution [Worster, 2002]. In contrast, local supersaturation in air above water or ice occurs because of the strongly nonlinear relationship between temperature and saturation density. Of most significance is that it can occur during evaporation or sublimation as well as during condensation, as we shall determine below.

[6] There are six regimes of possible behaviour of the system depending on the environmental conditions: the relative humidity of the atmosphere $\rho_{\infty} / \rho_{\text {sat }}\left(T_{\infty}\right)$ and the temperature difference between the atmosphere and the ice surface, as shown in Figure 3 and described in Table 1. If the actual temperature of the surface is greater or less than $0^{\circ} \mathrm{C}$ then the condensed phase is water or ice, which can evaporate or sublimate respectively. There is no qualitative difference between these processes as far as the saturation of the air near the interface is concerned and we shall use the terms interchangeably. The horizontal line in Figure 3 delineates the conditions under which the atmosphere is supersaturated $\left(\rho_{\infty} / \rho_{\text {sat }}\left(T_{\infty}\right)>1\right)$ from those under which it is unsaturated $\left(\rho_{\infty} / \rho_{\text {sat }}\left(T_{\infty}\right)<1\right)$.

[7] Water will condense from the air onto the surface if $\rho_{\infty}$ $>\rho_{i}$. Since the reduced temperature $\tau=\left(T_{\infty}-T_{i}\right) / T_{\infty} \ll$ 1 , this condition is only weakly dependent on the absolute temperature and we can approximate it, using equation (1), by

$$
\rho_{\infty} / \rho_{\text {sat }}\left(T_{\infty}\right)>e^{-m \tau},
$$

where $m=M L / R T_{\infty}$, which is represented by the long-dashed curve in Figure 3: there is condensation in the darkgrey-shaded regimes II, III and IV and evaporation/sublimation 
Table 1. Key to Figure $3^{\mathrm{a}}$

\begin{tabular}{|c|c|c|c|c|}
\hline \multirow[b]{2}{*}{ Regime } & \multirow{2}{*}{$\begin{array}{c}\text { Far Field } \\
\text { Characteristics }\end{array}$} & \multicolumn{2}{|c|}{ Surface Characteristics } & \multirow[b]{2}{*}{ Examples } \\
\hline & & $T_{\infty}-T_{i}<0$ & $T_{\infty}-T_{i}>0$ & \\
\hline I & Supersaturated & Evaporation Supersaturated & & Vigorous heating (without boiling) of water in mist. \\
\hline II & Supersaturated & Condensation Supersaturated & Condensation Supersaturated & Formation of snowflakes. Rime ice. \\
\hline III & Unsaturated & & Condensation Supersaturated & Advection fog. Previous laboratory frost flowers. \\
\hline IV & Unsaturated & & Condensation Unsaturated & Dew, frost, condensation on cold surfaces. \\
\hline $\mathrm{V}$ & Unsaturated & Evaporation Unsaturated & Evaporation Unsaturated & Simple evaporation or sublimation. \\
\hline VI & Unsaturated & Evaporation Supersaturated & & FROST FLOWERS. Condensed steam above a hot drink \\
\hline
\end{tabular}

${ }^{\mathrm{a}}$ In each regime, denoted by a roman numeral, the water/ice surface is either evaporating/sublimating or having water/ice condensing upon it, and the air adjacent to it is either supersaturated or unsaturated. In Table 1, 'Evaporation' stands for either evaporation or sublimation depending on the absolute temperature. Examples of phenomena associated with each regime are given in the final column.

in light-grey-shaded regimes I, V and VI. Perhaps surprisingly, regime I shows evaporation into a supersaturated atmosphere but this simply corresponds, for example, to a steaming mug of coffee on a cold misty morning. Conversely, regimes III and IV show condensation from an unsaturated atmosphere, corresponding to the misting up of the inside of cold window panes.

[8] Local supersaturation of the air adjacent to the condensed phase, as depicted in Figure 2, occurs when $\partial \rho / \partial z>$ $\partial \rho_{\text {sat }} / \partial z$ at the interface $z=0$. From equations (1) to (3), and taking the reduced temperature to be small, we can determine that this will occur when

$$
\rho_{\infty} / \rho_{\text {sat }}\left(T_{\infty}\right)>(1+m \tau) e^{-m \tau},
$$

depicted by the short-dashed curve in Figure 3. This analysis reveals two interesting regimes, III and VI, in which there is local supersaturation near the condensed phase even though the far-field atmosphere is unsaturated.

[9] Regime III occurs simply because relatively saturated, though not supersaturated, air comes into contact with a cold surface. This is regularly experienced as dew or ground frost. It is also likely that the previous laboratory experiments on frost flowers [Martin et al., 1995] operated in this regime, with moist, relatively warm air provided by the vaporizer condensing on the relatively cold ice surface.

[10] The most intriguing regime exposed by our analysis is regime VI, in which supersaturated air is produced adjacent to an ice surface sublimating into a relatively cold, dry atmosphere. This suggests that frost flowers can grow with no other source of water than the ice itself on which they form and that they can do so in calm conditions. This is in agreement with the experiments of Martin et al. [1996] who observed the presence of a supersaturated region above the sea ice into which frost flowers grew.

\section{Experiments}

[11] We have tested this prediction in our cold room. We had previously made several unsuccessful attempts at growing frost flowers without employing any extra vapour source, the air in the room being particularly dry. However, encouraged by the analysis presented above, we repeated our experiments with the simple expedient of making the room even colder. A series of experiments was performed in a perspex tank $25 \mathrm{~cm} \times 25 \mathrm{~cm} \times 38 \mathrm{~cm}$, insulated at bottom and sides with $10 \mathrm{~cm}$-thick polystyrene and filled to a depth of $10 \mathrm{~cm}$ with either fresh or salty water $(33 \mathrm{ppt} \mathrm{NaCl}$ by weight). The top was covered with a coarse plastic grid to allow good heat and water-vapour exchange while reducing the influence of forced air flow from the coolers. In order to maintain a thin layer of ice $(1-2 \mathrm{~cm})$, the tank bottom was heated to $5^{\circ} \mathrm{C}$. The ice anchored itself to the tank walls and the volume expansion upon freezing led to bulging of the ice surface in the case of fresh water or flooding of the surface of porous sea ice grown from salt water, which was found to prevent frost flower growth. To mediate these effects and simulate floating sea ice, a collapsible bag containing methanol was placed within the liquid and connected to an external reservoir that could be adjusted to relieve the build-up of pressure below the ice.

[12] Temperature in the air above the ice was measured by a thermistor array, and relative humidity by a hand-held probe. Given the linearity between temperature and vapour density implied by equations (2) and (3), the temperature and humidity can be taken at several heights above the interface (not just in the far field) in each experimental run and plotted on the same regime diagram (Figure 4). We see that equation (5) accurately predicts when supersaturation was observed above the ice (supersaturation being indicated

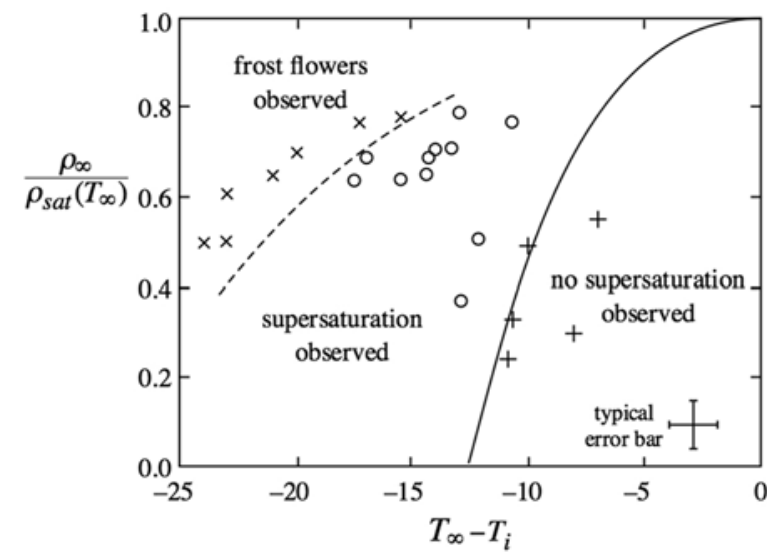

Figure 4. Experimental results showing the relative humidities $\rho_{\infty} / \rho_{\text {sat }}\left(T_{\infty}\right)$ and temperature differences $T_{\infty}-$ $T_{i}$ between the atmosphere and the ice surface at which: no evidence of supersaturation was observed (plusses); there was evidence of supersaturation but no frost flowers formed (circles); or frost flowers were observed on the ice surface (crosses). The solid curve shows the prediction of equation (5) with parameter values $M L=5.09 \times 10^{4} \mathrm{~J} \mathrm{~mol}^{-1}, R=$ $8.31 \mathrm{~J} \mathrm{~K}^{-1} \mathrm{~mol}^{-1}$ and $T_{\infty}=272 \mathrm{~K}$, giving $m=22.5$. The dashed curve is an empirical fit to the data corresponding to equation (5) with $m \approx 10$. 
by the presence of frost on instruments directly above the ice surface, and on the sidewalls of the tank). However, frost flowers only formed at larger values of supersaturation.

\section{Discussion}

[13] We have performed a linear morphological stability analysis of the ice surface, including the effects of vapour transport by air flow generated by the sublimating ice. These affect the growth rate of instabilities but not the condition for instability which, neglecting surface energy, is similar to that for morphological instability of a binary alloy [Mullins and Sekerka, 1964], namely that

$$
\frac{\partial \rho}{\partial z}>\frac{\partial \rho_{s a t}}{\partial T} \frac{k_{a}(\partial T / \partial z)_{a}+k_{s}(\partial T / \partial z)_{s}}{k_{a}+k_{s}},
$$

involving the conductivity-weighted temperature gradient. If the thermal conductivities $k_{a}$ and $k_{s}$ of air and solid were equal then condition (6) would be approximately equal to (5): the ice-air interface would be linearly unstable whenever there is local supersaturation above it. However, because $k_{s} \gg k_{a}$, stability is dominated by the heat flux through the ice, the right-hand side of equation (6) is approximately $2\left(k_{a} / k_{s}\right)\left(\partial \rho_{s a t} / \partial z\right)_{a}$, which is very small, and the interface is stable unless condition (4) is met: unless vapour is condensing onto it. In the interesting regime VI, the ice-air interface is linearly stable. However, we have also determined that sufficiently large, finite-amplitude disturbances can grow even when the system is linearly stable. In particular, highaspect-ratio spikes or sheets can grow into the locally supersaturated vapour above it, as they have poor thermal contact with the underlying ice and so are minimally affected by heating from the ice despite its high heat conductivity. These considerations indicate that frost-flower formation is a nucleated process [Martin et al., 1995] requiring sufficiently large seed crystals, which might be provided by ice crystals in the air ('diamond dust') or by ice platelets protruding from sea ice, for example. We expect that frost flowers are harder to nucleate on sea ice owing to smaller crystals being engulfed by the surface brine layer leaving frost flowers to be nucleated from a smaller number of larger crystals. Therefore we also expect that frost flowers will be more widely spaced on sea ice than on the fresh-water ice we used in our laboratory experiments shown in Figure 1c.

[14] Once formed, the growth of frost flowers will be limited by the thickness of the supersaturated layer. That thickness is determined by environmental conditions, influenced by both forced convection (wind) and natural, buoyancy driven convection resulting from water vapour produced during sublimation.

\section{Conclusions}

[15] Our analysis and laboratory experiments show that frost flowers can grow into an unsaturated atmosphere provided that the temperature difference between the ice surface and the atmosphere is sufficiently large. This explains why frost flowers are commonly seen on very young sea ice in recently relaminated leads and polynyas, whose surface is warm relative to the atmosphere owing to the proximity of the underlying sea water, while not forming on neighbouring, thicker ice floes [Perovich and Richter-Menge, 1994]. It also explains why frost flowers are short-lived phenomena: as sea ice grows thicker its surface temperature approaches that of the atmosphere (moving the system from regime VI to regime V) and the flowers simply sublimate away. Though more rarely seen on the surface of frozen freshwater ponds, frost flowers can form there if the atmospheric temperature falls sufficiently rapidly (below about $-15^{\circ} \mathrm{C}$ ) before the ice has grown very thick. Frost flowers are typically only seen at wind speeds below about $5 \mathrm{~m} \mathrm{~s}^{-1}$ : at higher wind speeds turbulence mixes the region of local supersaturation with the drier air above. The very high surface areas of frost flowers help to wick up brine from the interstices of the underlying sea ice and provide sites for production of $\mathrm{BrO}$.

[16] Several other natural phenomena involving condensation and evaporation or sublimation, such as dew, fog and Jack Frost, can be understood and quantified using the analysis we have presented. The same fundamental ideas apply equally to industrial processes involving physical vapour deposition, for example. Thus, ice is not only important in our environment but provides a physical model by which many aspects of phase transformation can be studied.

[17] Acknowledgments. This work was supported by a Case studentship from the Natural Environment Research Council in collaboration with the British Antarctic Survey. We thank HE Huppert, JA Neufeld, D Notz, JS Wettlaufer and EW Wolff for their thoughtful readings of the manuscript.

\section{References}

Domine, F., A. S. Taillandier, W. R. Simpson, and K. Severin (2005), Specific surface area, density and microstructure of frost flowers, Geophys. Res. Lett., 32, L13502, doi:10.1029/2005GL023245.

Huppert, H. E., and M. G. Worster (1985), Dynamic solidification of a binary melt, Nature, 314, 367-370.

Kaleschke, L., et al. (2004), Frost flowers on sea ice as a source of sea salt and their influence on tropospheric halogen chemistry, Geophys. Res. Lett., 31, L16114, doi:10.1029/2004GL020655.

Martin, S., R. Drucker, and M. Fort (1995), A laboratory study of frost flower growth on the surface of young sea ice, J. Geophys. Res., 100, $7027-7036$.

Martin, S., Y. Yu, and R. Drucker (1996), The temperature dependence of frost flower growth on laboratory sea ice and the effect of the flowers on infrared observations of the surface, J. Geophys. Res., 101, $12,111-12,125$

Mullins, W. W., and R. F. Sekerka (1964), Stability of a planar interface during solidification of a dilute binary alloy, J. Appl. Phys., 35, 444-451.

Perovich, D. K., and J. A. Richter-Menge (1994), Surface characteristics of lead ice, J. Geophys. Res., 99, 16,341-16,350.

Rankin, A. M., E. W. Wolff, and S. Martin (2002), Frost flowers: Implications for tropospheric chemistry and ice core interpretation, J. Geophys. Res., 107(D23), 4683, doi:10.1029/2002JD002492.

Reed, T. B., and W. J. LaFleur (1964), Constitutional supercooling in iodine vapor crystal growth, Appl. Phys. Lett., 5, 191-193.

Rutter, J. W., and B. Chalmers (1953), A prismatic substructure formed during solidification of metals, Can. J. Phys., 31, 15-31.

Wolff, E. W., A. M. Rankin, and R. Röthlisberger (2003), An ice core indicator of Antarctic sea ice production?, Geophys. Res. Lett., 30(22), 2158, doi:10.1029/2003GL018454.

Worster, M. G. (2000), Solidification of fluids, in Perspectives in Fluid Dynamics, edited by G. K. Batchelor et al., pp. 393-446, Cambridge Univ. Press, Cambridge, U. K.

Worster, M. G. (2002), Interfaces on all scales, in Interfaces for the 21st Century, edited by M. K. Smith et al., pp. 187-201, Imp. Coll. Press, London.

R. W. Style and M. G. Worster, Institute of Theoretical Geophysics, Department of Applied Mathematics and Theoretical Physics, University of Cambridge, Centre for Mathematical Sciences, Wilberforce Road, Cambridge CB3 0WA, UK. (grae@damtp.cam.ac.uk) 